\title{
MPPT CHARGE CONTROLLER
}

\author{
Deepika Saikia \\ Department of ECE \\ MIT ADT UNIVERSITY, Pune \\ Maharashtra, India
}

\author{
Karrman Bhatia \\ Department of ECE \\ MIT ADT UNIVERSITY, Pune \\ Maharashtra, India
}

\author{
Prajakta Powar \\ Department of ECE \\ MIT ADT UNIVERSITY, Pune \\ Maharashtra, India
}

\begin{abstract}
In this project, design of MPPT charge Controller shows as a buck-boost converter. This buckboost converter is to maintain the constant output voltage as well as abstracts the more additional available power from the photovoltaic module. This system is based on constant voltage tracking method. This system consists of buck-boost converter. Also, it includes ACS 712 current sensor, LCD display, microcontroller, MOSFET circuit, coil burner as a load.
\end{abstract}

Keywords - Photovoltaic module, buck-boost converter method, Burner coil(load),current sensor, Ferrite core transformer.

\section{INTRODUCTION}

Now a day's, most of works are depends on electricity. so, demand of electricity is increased by day to day. But cost of generating power is more. So, for that problem, we find out the solution. We have a solar energy. It is pollution free and sustainable energy. By using this solar energy we have implemented the MPPT charge controller technique. MPPT is a maximum power point tracking charge controller to track the operating point and keep the maximum power point at highest efficiency. PV module is to deliver the available power. MPPT harvested more power from PV module and store into battery.

So, battery charge current will increased and then the system efficiency also improved. By generating the electricity using this technique is more helpful to reduce the power generating cost. From many researches on generation of electricity, we found that MPPT technique is most efficient and economical to generate electricity. The Microcontroller is used only for displaying the voltage, current and power. A charge controller is used to regulates the charge to battery and avoiding overcharging.

\section{A. BUCK CONVERTER}

It is a DC-DC power converter which steps down the voltage or step up the current from its input to output. Also it is converter which DC input Voltage is greater than DC output voltage. original image, lower left corner of the vertical details, upper right corner of the horizontal details, lower right corner of the component of the original image detail (high frequency). You can then continue to the low frequency components of the same upper left corner of the 2nd, 3rd inferior wavelet transform.

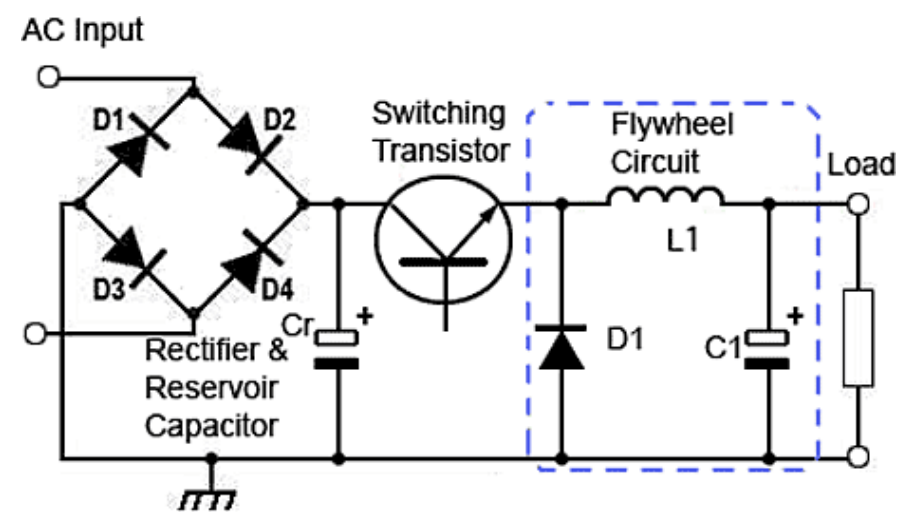

Fig1. Buck converter circuit

The buck converter is a form of DC-DC converter that can take an input from DC source as a battery and also it could be DC derived from main AC supply through the rectifier capacitor circuit[1]. The AC input supply is gives to the rectifier circuit or it can be alternate the voltage by step-down transformer. so, the DC voltage is applied to the buck converter circuit.

Then, this DC voltage is converter into AC voltage by chopper or switching transistor. Again it will be reconverted into original DC voltage. Always, it maintain the constant the output voltage if input supply is does not get the properly and if the input supply is maximum vary.

In winter, time of sunrays are very low. Butwe need the more power to charge the battery. So, at that time, boost converter is widely used to extracts maximum power and charge the battery. 


\section{International Journal of Engineering Applied Sciences and Technology, 2021 \\ Vol. 6, Issue 2, ISSN No. 2455-2143, Pages 280-283 \\ Published Online June 2021 in IJEAST (http://www.ijeast.com)}

\section{B. BOOST CONVERTER}

It is a step up converter which steps up voltage or step down current from its supply to load. This converter which DC input voltage is less than the DC output voltage. These converters provides the maximum power efficiency. It step up the input voltage to the required output voltage. An Inductor, aDiode and a high frequency switch is the main part ofboost converter[2].

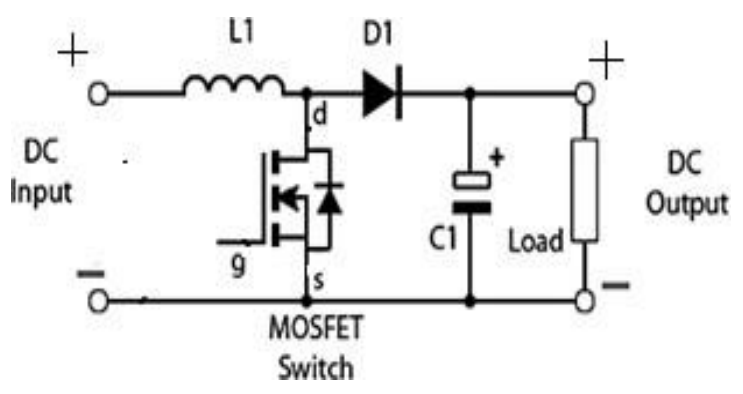

Fig 2. Boost converter circuit

When the switch is ON, the inductor output is connected to ground and voltage Vin across it.so, the inductor current increases at $\mathrm{Vin} / \mathrm{L}^{[5]}$. When the switch ids OFF, voltage across the inductor is changed. So the output voltage equal to input voltage. The boost converter is harvested the Maximum current from the photovoltaic module. In summer, time of sunrays are more. So, more sunrays are followed on the PV module and maximum power stored into the battery. If we used buck converter, it maintain the constant output and prevent overcharge the battery.

\section{SYSTEM REQUIREMENT}

\section{A. ATmega 328p Microcontroller}

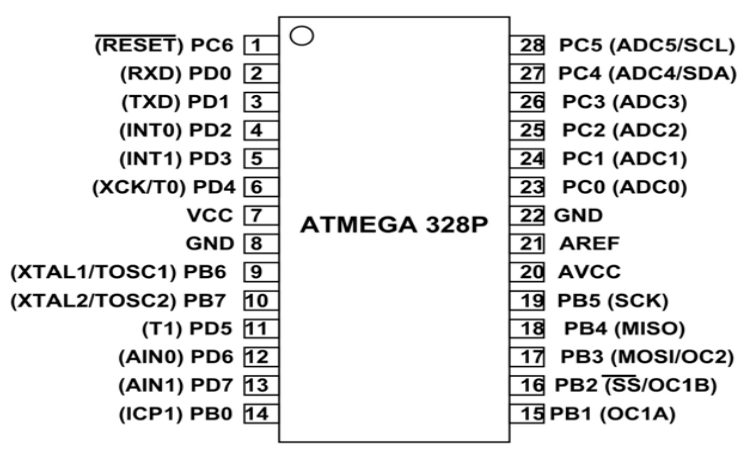

Fig. 3 ATmega328p
Arduino Uno is a microcontroller board based on the ATmega328P . It has 14 digital input/output pins (of which 6 can be used as PWM outputs), 6 analog inputs, a $16 \mathrm{MHz}$ quartz crystal, a USB connection, a power jack, an ICSP header and a reset button. It contains everything needed to support the microcontroller, simply connect it to a computer with a USB cable or power it with a AC-to-DC adapter or battery to get started. You can tinker with your UNO without worrying too much about doing something wrong, worst case scenario you can replace the chip for a few dollars and start over again.

"Uno" means one in Italian and was chosen to mark the release of Arduino Software (IDE) 1.0. The Uno board and version 1.0 of Arduino Software (IDE) were the reference versions of Arduino, now evolved to newer releases. The Uno board is the first in a series of USB Arduino boards, and the reference model for the Arduino platform.

\section{B. Buck Boost converter}

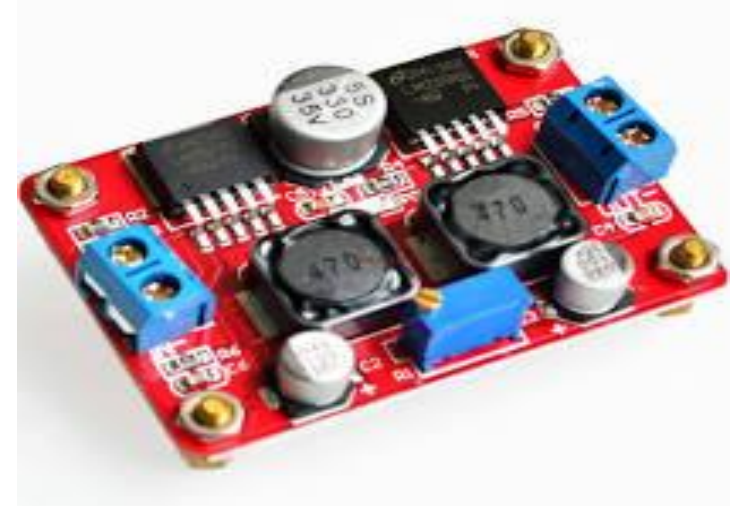

Fig. 4 Buck Boost converter

A buck-boost converter is a type of SMPS (SwitchMode Power Supply) that uses the same concept of both a buck converter and a boost converter, but in one combined circuit. The main objective of a buck-boost converter is to receive an input DC voltage and output a different level of DC voltage, either lowering or boosting the voltage as required by the application. The design of a buck-boost converter is similar to a buck converter and boost converter, except that it is in a single circuit and it usually has an added control unit. The control unit senses the level of input voltage and takes appropriate action on the circuit based on that voltage.

\section{MPPT Charge controller(Maximum Power Point Tracking)}




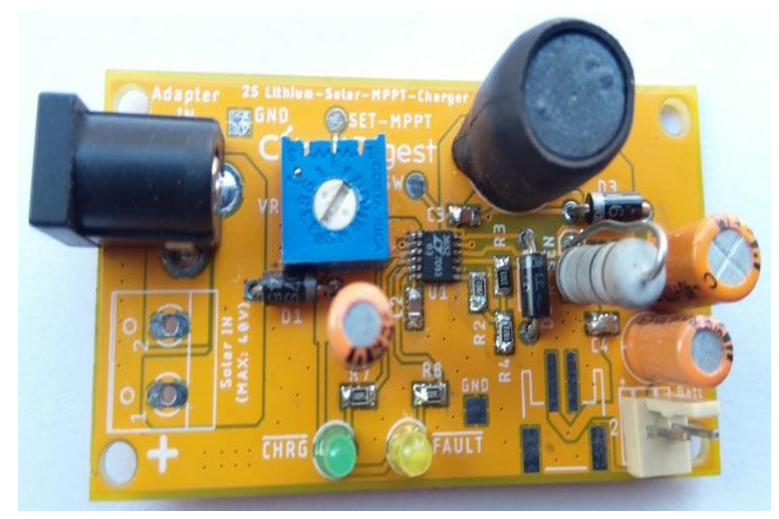

Fig 5 MPPT Charge controller

MPPT or 'maximum power point tracking' controllers are far more advanced than PWM controllers and enable the solar panel to operate at its maximum power point, or to be more precise, the optimum voltage for maximum power output. Using this clever technology, MPPT solar charge controllers can be up to $30 \%$ more efficient, depending on the battery voltage and voltage of the solar panel connected

\section{Voltage Sensor}

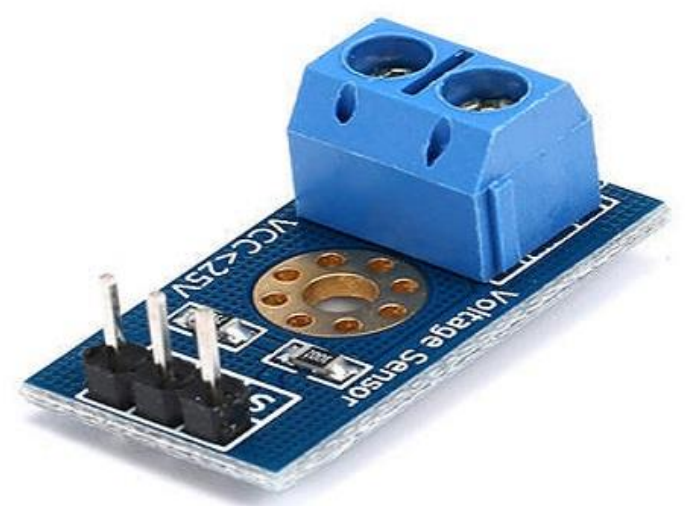

Fig. 6 Voltage Sensor

A voltage sensor is a sensor used to calculate and monitor the amount of voltage in an object. Voltage sensors can determine the AC voltage or DC voltage level. The input of this sensor is the voltage, whereas the output is the switches, analog voltage signal, a current signal, or an audible signal.

Sensors are devices that can sense or identify and react to certain types of electrical or optical signals. The implementation of a voltage sensor and current sensor techniques have become an excellent choice for the conventional current and voltage measurement methods.
III. WORKING

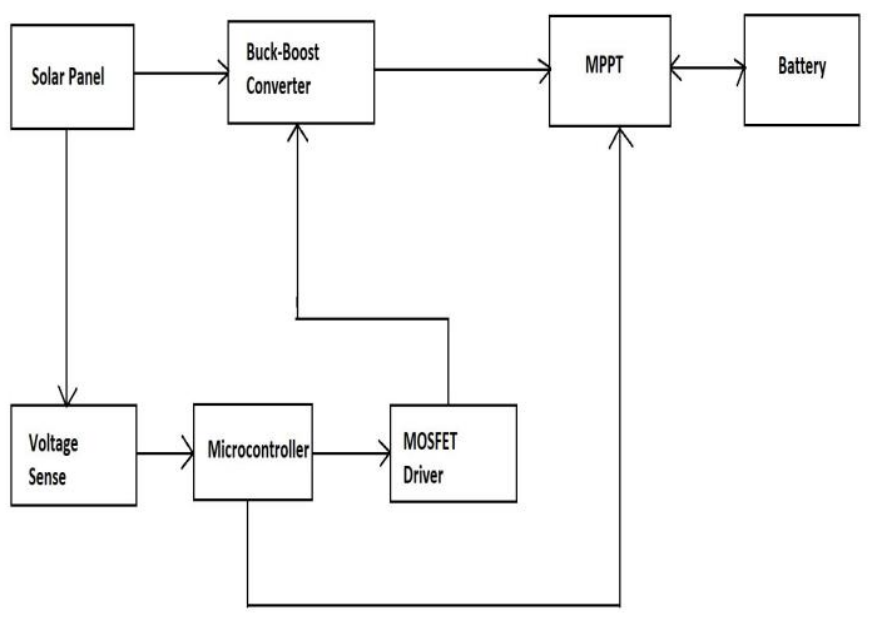

Fig 7 Block Diagram

Maximum Power Point Tracking is electronic tracking usually digital. The charge controller looks at the output of the panels and compares it to the battery voltage. It then figures out what is the best power that the panel can put out to charge the battery. It takes this and converts it to best voltage to get maximum AMPS into the battery. (Remember, it is Amps into the battery that counts). Most modern MPPT's are around 93$97 \%$ efficient in the conversion. You typically get a 20 to $45 \%$ power gain in winter and $10-15 \%$ in summer. Actual gain can vary widely depending weather, temperature, battery state of charge, and other factors.

\section{How Maximum Power Point Tracking works}

Here is where the optimization or maximum power point tracking comes in. Assume your battery is low, at 12 volts. An MPPT takes that 17.6 volts at 7.4 amps and converts it down so that what the battery gets is now 10.8 amps at 12 volts. Now you still have almost 130 watts, and everyone is happy.

Ideally, for $100 \%$ power conversion you would get around 11.3 amps at 11.5 volts, but you have to feed the battery a higher voltage to force the amps in. And this is a simplified explanation - in actual fact, the output of the MPPT charge controller might vary continually to adjust for getting the maximum amps into the battery.

The power point tracker (and all DC-to-DC converters) operates by taking the DC input current, changing it to $\mathrm{AC}$, running through a transformer (usually a toroid, a doughnut looking transformer), and then rectifying it back to DC, followed by the output regulator. In most DC-to-DC converters, this is strictly an electronic process - no real smarts are involved except for some regulation of the output voltage. 
Charge controllers for solar panels need a lot more smarts as light and temperature conditions vary continuously all day long, and battery voltage changes.

\section{SIMULATION}

\section{A. Buck-Boost Converter}

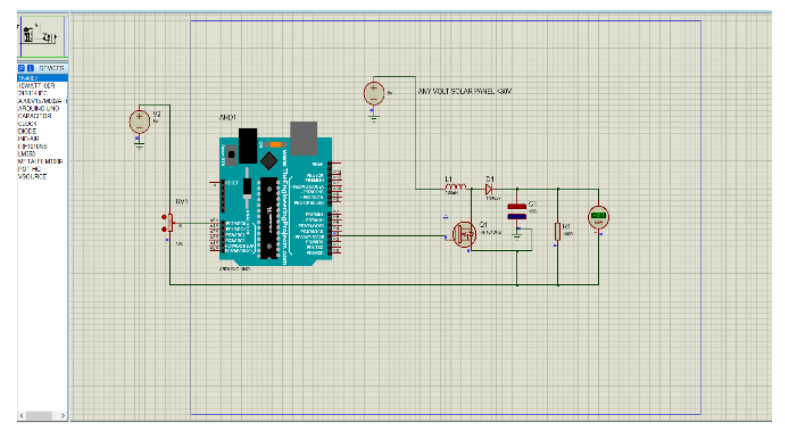

Fig 8 Buck Boost Converter

\section{B. Complete Simulation of the project}

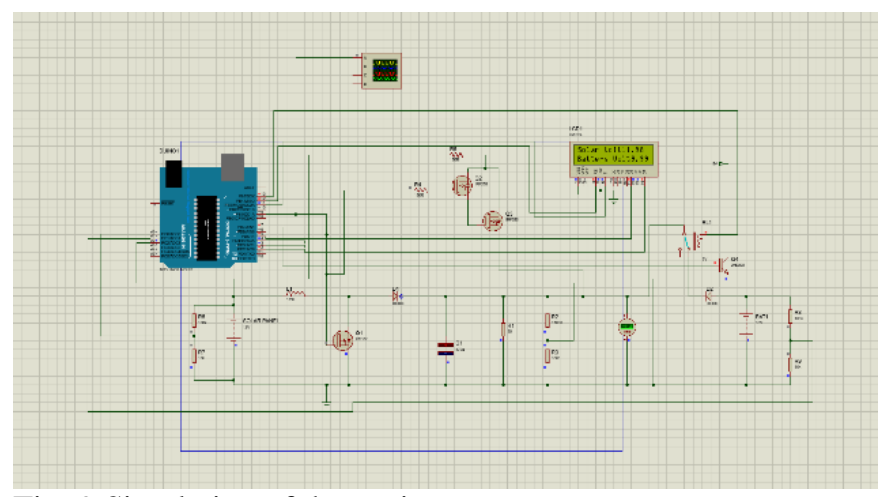

Fig 9 Simulation of the project

This is the main simulation of project. Here from R6 =R7 and solar panel we get raw voltage means this voltage is of solar panel. Next after solar panel buck-boost converter is there for maintain the voltage level. When we are getting voltage less than $12 \mathrm{~V}$ from solar panel but we need input voltage as $12 \mathrm{~V}$ then the boost converter will work and it increases the voltage level and when we are getting voltage more then $12 \mathrm{~V}$ from solar panel then buck converter will work and it decreases the voltage level.

Now when we are getting exact voltage which we need then the current will flow through R5, Q2 and Q3 MOSFET is ON. Q2 and Q3 are connected in Darlington pair where we have maximum gain, current and voltage. Here we get maximum voltage and current to charge the battery.
We connect the battery through relay because incase if we get garbage value the battery can be destroyed so for security purpose, we add the relay.

\section{V.CONCLUSION}

This project presents analog circuit of MPPT charge controller. We get a better battery protection from overvoltage using Optocoupler and MOSFETs. This project presents analog circuit of MPPT charge controller using LM324. We get a better battery protection from overvoltage using Optocoupler and MOSFETs. The perturb observe method gives boosted results by comparator and use of Arduino to interface LCD and Bluetooth module helps to monitor the results technique. This method presented here control lead acid battery charging faster and efficiently. The control algorithm execute $\mathrm{P} \& \mathrm{O}$ method allow module to operate at maximum power point according to solar irradiation, and match load with the source impedance to provide maximum power. This MPPT model is more suitable because of less cost, easier circuit design. And efficiency of the circuit is increased by $20-25 \%$ in case of MPPT solar charge controller compare to a circuit without MPPT. And also saved the extra energy required in mechanical tracking. As Arduino based controlling is used, it maintained constant $12 \mathrm{~V}$ at the output terminal i.e., at the battery terminal.

\section{REFERENCE}

[1] Vikas R. Gurav1, Sunil S.patil2, Akshay S.Salokhe3, Mr.P.V.Kothawale4 proposed the design of MPPT charge Controller shows as a buck-boost converter.

[2] Sunil Kumar Mahapatro proposed a project that boost converter is to be used along with a Maximum Power Point Tracking control mechanism.

[3] T.Sridhar 1, Anish kumar J 2 proposed a project work that introduces an approach to design a boost converter for photovoltaic (PV) system using microcontroller. 